\title{
Digitalisation in Agriculture: Knowledge and Learning Requirements of German Dairy Farmers
}

\author{
Michael Goller ${ }^{\star 1,2}$, Carina Caruso ${ }^{1}$, Christian Harteis ${ }^{1}$ \\ ${ }^{1}$ Paderborn University, Institute of Educational Science, Warburger Str. 100, \\ 33098 Paderborn, Germany \\ ${ }^{2}$ Friedrich Schiller University Jena, Institute of Educational Science, Fürstengraben 1, \\ 07743 Jena, Germany
}

Received: 10 February 2021, Accepted: 31 May 2021

\begin{abstract}
Purpose: This study aims at investigating how digitalisation (in the sense of industry 4.0) has changed the work of farmers and how they experience the changes from more traditional work to digitalised agriculture. It also investigates what knowledge farmers require on digitalised farms and how they acquire it. Dairy farming was used as domain of investigation since it, unlike other industries, has strongly been affected by digitalisation throughout the last years.
\end{abstract}

Method: Exploratory interviews with 10 livestock farmers working on digitalised dairy farms were analysed using qualitative content analysis. A deductive and inductive coding strategy was used.

Findings: Farming work has changed from more manual tasks towards symbol manipulation and data processing. Farmers must be able to use computers and other digital devices to retrieve and analyse sensor data that allow them to monitor and control the processes on their farm. For this new kind of work, farmers require elaborated mental models that link traditional farming knowledge with knowledge about digital systems, including a strong understanding of production processes underlying their farm. Learning is mostly based on instructions offered by manufacturers of the new technology as well as informal and

*Corresponding author: michael.goller@upb.de 
non-formal learning modes. Even younger farmers report that digital technology was not sufficiently covered in their (vocational) degrees. In general, farmers emphasises the positive effects of digitalisation both on their working as well as private life.

Conclusions: Farmers should be aware of the opportunities as well as the potential drawbacks of the digitalisation of work processes in agriculture. Providers of agricultural education (like vocational schools or training institutes) need to incorporate the knowledge and skills required to work in digitalised environments (e.g., data literacy) in their syllabi. Further studies are required to assess how digitalisation changes farming practices and what knowledge as well as skills linked to these developments are required in the future.

Keywords: Work-Based Learning, Organisational Change, Digital Competences, Qualitative Research, Digitalisation, Farming, Dairy, VET, Vocational Education and Training

\section{Introduction}

Digitalisation within professional contexts describes an ongoing process of introducing computerised technology with the aim of automatising work processes. To be more precise, the core quality of industrial digitalisation lies in the integration of software components as well as mechanical and electrical hardware parts that can exchange information over a network in order to add some kind of value, such as a flexible production system or reduced manpower requirements (Harteis, 2018). With the help of sensor technology, actuators, and elaborated software algorithms that are all integrated in a so-called cyber-physical system (CPS), it is possible to represent and manipulate working processes on computers in such a way that they can be automatised and controlled centrally from distance (e.g., Kagermann, 2015; see, for the agricultural context, Wolfert et al., 2017).

As with all technological changes in the past, it must be assumed that these digitalisation efforts have strong potential to transform the domain of work for many if not all employees (Frey \& Osborne, 2017; see however Pfeiffer, 2018). The scenarios concerning this transformation discussed in the literature differ (Dworschak \& Zaiser, 2014). While some scholars assume in the automation scenario that digital technology will replace all tasks now performed by humans-as long as it is not too complex to do so or if it is otherwise economically inefficient-others believe that work will mostly be relieved of menial or dangerous tasks, allowing humans to take over meaningful work requiring creativity or other kinds of cognitive capacity (specialisation scenario). Besides these disagreements within the literature, however, consensus exists among a range of authors that digitalised workplaces will qualitatively change work practices and therefore also require knowledge and skills that are different from before (Al-Ani, 2017; Letmathe \& Schinner, 2017). 
Both scenarios similarly assume that manual work will largely be taken over by machines and only special cases will exist in which humans still have to engage in such tasks. It rather seems plausible that human workers are more often concerned with overseeing and controlling the systems in use. In other words, most of the time workers must mentally analyse and interpret data provided by the systems to make sense of it instead of physically manipulating tools and artefacts. This requires workers to be digitally literate-that is, being competent both to deal with computer systems that provide data as well as to use effectively the provided information units in meaningful and critical ways to manage production processes constructively (World Economic Forum, 2016).

In addition, workers need a better understanding of production processes at work instead of just being competent to engage in a particular set of concrete working tasks. Without good knowledge about how production is organised, how the different parts of the particular CPS are integrated with each other, and how the decision-making within the complex system is controlled by algorithms, it is hardly possible that workers are able to oversee and manage automatised production processes or to intervene in cases of problems and failure in a competent way (Harteis, 2018). Taken together, work seems to become more knowledge demanding and, while some knowledge components might not be needed any more, others that are related to the interaction with computer-based machinery and peripheral devices are asked for much more.

It remains, however, largely unknown how workers who are directly affected by digitalisation acquire the knowledge and skills required to deal with computerised working and production processes. Due to the cutting-edge nature of digitalisation it must be assumed that neither the current (vocational) education system nor existing further education courses are able to prepare workers adequately for what to expect in digitalised working environments (Harteis et al., 2019). It follows that especially the first generation of affected workers must develop the required knowledge through (non)formal and informal learning directly at work. The problem with this mostly experience-based learning is that it might not be very efficacious in the context of digitalisation because automatised work processes run hidden from their human end-users. As Billett (2018) argues, digitalised work can often not be experienced directly due to its opaque and abstract character. In the worst case, workers might not be able to construct appropriate mental models that help them to understand the systems in use. From an educational perspective this questions workers' professional agency since they are rendered ineffective to exercise control and to emancipate themselves effectively from external forces (Eteläpelto et al., 2013; Harteis, 2018; Goller, 2017). From a more technical perspective this could lead to the irony of automation describing workers as unable to respond effectively in cases where the digital system breaks down (Bainbridge, 1983).

Within the majority of work domains, efforts to digitalise production processes are either still in the planning phase or have just begun. In stark contrast, agriculture-and especially 
livestock farming - was one of the first major industries affected by digitalisation efforts and many farmers can be described as pioneers in introducing integrated systems of sensors, actuators, and software algorithms to automatise working processes (Götz \& Duda, 2018; Herlitzius, 2018; OECD, 2019). In fact, a high share of agricultural enterprises already employs this technology-often under the label of precision or smart farming (Eastwood et al., 2017) - to make use of available input resources both more efficiently and effectively (see e.g., Sponchioni et al., 2019). For instance, within the context of pig or cattle farming, automatised and individual feeding machines based on performance and health parameters help to reduce fodder requirements while producing the same or even higher yields. Another example is automatised gate systems that help to sort animals without the use of manpower. One of the strongest distributions of digital technology, however, has been recorded in dairy cattle farming (Vik et al., 2019). Besides the already described examples, it is the use of fully automatised milking robots as well as wearable sensors that allow a range of relevant health and performance data to be gathered and integrated within the herd management systems that are commonly utilised in this context (OECD, 2019).

In general, most discussions around the effects of digitalisation on the world of work are led either on speculative grounds or very general forecasts regarding job profiles (e.g., Frey \& Osborne, 2017). It is because of the cutting-edge character of the digitalisation in most domains that almost no empirical studies exist about how the change from more traditional to digitalised work is experienced by workers, what knowledge is required, and how it is learned (see, however, Fischer et al., 2018). And although the agricultural domain has been affected by this digitalisation, only a few empirical studies shed light on these open issues (Butler et al., 2012; Holloway et al., 2014; Vik et al., 2019). These studies, conducted mainly in Norway and the UK, found the first evidence that digital farming increases flexibility during the working day, requires more technical knowledge and skills, and also changes the quantitative and qualitative relationship between farmers and their animals. Unfortunately, no comparable findings exist for the German context although it is one of the main agricultural producers in the European Union. In addition, studies adopting an educational perspective on digitalisation trends in farming are completely missing.

The aim of this study is to address this research gap with an explorative study in the context of German dairy farming. To be more concrete, several interviews with farmers whose farms have undergone considerable digital change were conducted to answer the following research questions:

(1) How do farmers experience the changes from more traditional work to digitalised agriculture?

(2) What knowledge do farmers require on digitalised farms and how do they acquire it? 
By answering these research questions this study significantly adds to the existing literature about the effects of digitalisation of farming from an educational perspective, especially by taking the German context into account. The next section will describe the methodology underlying this study, including the materials used. It is followed by a description and discussion of the findings.

\section{Materials and Method}

To answer the research questions this study used an explorative interview approach. To find potential interview participants, a wide range of dairy farms in the north of North Rhine-Westfalia and the south of Lower-Saxonia in Germany were contacted via phone and mail. Criterion for potential inclusion into the sample was that the farms-the participants work at-introduced at least some kind of digitalisation in the last years that resulted in automatised work processes as described in the theoretical part of this contribution. In sum, 10 farmers ( 1 female) from nine different dairy farms that met this criterion agreed to take part in the study (convenience sample). Both the size of the farms (on average 145 dairy cattle, $\operatorname{Min}=60, \operatorname{Max}=400$ ) and their commercial organisation mode (mostly family owned) are quite typical for Germany (FMFA, 2016). All interview partners held at least a vocational farming degree, while a few even earned some kind of university qualification (mostly Bachelor level). Most farms had installed fully automatised milking robots $(k=6)$ or at least automatised milk analysis technique $(k=8)$ as part of their digitalisation strategy a few years ago. In addition, automatic scrapers and floor cleaning robots, automatised feeding machines, heat identification sensors, calving monitoring, and automatised gate systems were in use on some but not all farms. On most farms these technologies are interconnected via intranet or internet and make use of a centralised farm management system. All interview participants were familiar with both traditional and digitalised farming work.

The interviews were conducted using a semi-structured interview guideline containing open questions regarding how the farming practice had changed due to the digital equipment introduced, the changed knowledge and skill requirements, as well as how the necessary knowledge and skills were acquired. On average the interviews took about 50 minutes (SD $=24: 30$ minutes). After obtaining consent from participants, all interviews were recorded and subsequently transcribed verbatim. The more than 50,000-word-long transcripts were then analysed using qualitative content analysis based on the recommendations outlined in Kuckartz (2014) and Schreier (2012). In a first step, a combined deductive and inductive coding strategy was used to structure the interview material employing the following main categories (see Table 1): (a) Digitalisation at the farm, (b) Changes of farming practice, (c) Knowledge requirements, and (d) Learning modes. The transcripts were parallelly coded by the first two authors. In a second step, all coding discrepancies were discussed. Using a consent 
approach, it was decided which category to use. In the third step the first author paraphrased all remaining 317 codings and then summarised each coding in a single short proposition. These propositions were then used for extracting the main themes emerging from the interview material that will be reported and discussed below.

Table 1: Categories Used in Qualitative Content Analysis

\begin{tabular}{ll}
\hline Main Category & Definition \\
\hline (a) Digitalisation at the farm & $\begin{array}{l}\text { All kinds of descriptions concerning what digital technology was introduced at the farm } \\
\text { and why. }\end{array}$ \\
(b) Changes of farming practice & $\begin{array}{l}\text { All kinds of descriptions concerning how farming practices and work processes changed } \\
\text { due to the digital technology introduced at the farm (new tasks, ceased tasks, qualitative } \\
\text { change of tasks, changes concerning the relationship to livestock). }\end{array}$ \\
(c) Knowledge requirements & $\begin{array}{l}\text { All kinds of descriptions about knowledge and skills that are required to cope with the } \\
\text { new digital technology at the farm as well as descriptions that contrast competence } \\
\text { requirements before and after digitalisation. } \\
\text { All kinds of description of how the competences required to engage with digital farming } \\
\text { technology has been or is acquired. }\end{array}$ \\
\hline
\end{tabular}

\section{Findings}

\subsection{Changes Induced by Digitalisation}

All participants reported extensively and enthusiastically about the digital technology they are using on their farms. The changes induced by digitalisation were strongly associated with a new and desirable mode of working on their farms. Daily work routines on digitalised farms were described as less physically demanding and as requiring less time to be spent within the cowshed. To be more precise, it is the manual and labour-intensive milking process especially that has now been taken over by milking robots; as well, the frequent on-site monitoring of cattle is now being done by sensor technology (e.g., checking whether a cow has eaten). In general, farmers reported that they now have less direct contact with their livestock on the farm. Animals have only to be checked upon if indicated by the digital system (e.g., because of unusual sensor data). In relation to this, work is now described as less dirty and less strenuous. In general, these changes were experienced as a positive development by the interview participants.

Instead of the more manual work, farmers have now to engage more often in tasks that can best be described as monitoring and controlling the technology in use. To be more precise, farmers now spend a substantial part of their day analysing data reported by different sensors available in their equipment (e.g., amount of milk given or certain health parameters, etc.) and putting in new data required by the system (e.g., certain medication that lets the system 
know that the milk of a particular cow cannot be further processed). Data analysis is mostly done by focussing on deviations from established norms or historical records (e.g., quantity or composition of milk). This way, cattle can be identified that might be ill or that show other unusual tendencies (e.g., being in heat or pregnant) and that require the farmer to take certain measures. Both data analysis and data input are done using either personal computers or mobile devices like smartphones and tablets.

For example norm deviances regarding physical activity. A cow has a certain amount of walking that it usually does. And if she is in heat, she is excited, has a different kind of rhythm suddenly. And this more of physical activity that I get on the computer in form of a graph. Graphs or plain numbers, but graphs are better, because there I see peaks immediately and know "Ah, that is where I need to pay attention". (Interview 5)

In regard to the digital technology used at the farms, the interviewees agreed that both maintenance and cleaning of the machines are also part of their regular work. However, it was emphasised that maintenance is constrained to mechanical issues like changing wearing parts. In contrast, problems with the built-in electronics or software were described as out of the scope of their capacities. If such issues occur the farmers need to get help from external service technicians. Usually this maintenance service is provided by the manufacturer of the technology in use.

Work on digitalised farms was described as affording more temporal and geographic flexibility. The reasons for this increased flexibility lie in the interconnection of different sensors, machinery such as robots, and computers within a single system that allow to monitor and control farm equipment as well as working processes remotely. Using a computer or smartphone has made it possible for farmers to access data and to steer machinery without being present on site. The highest degree of flexibility is linked to autonomous milking robots that are being used at the farms. In this case, the daily work schedule is no longer determined by the cattle's need to be milked for two hours, once in the morning and once in the evening. This newly gained time and the new degrees of freedom can be used for other duties or even for recreational purposes.

At the same time, the farmers emphasised that the digital technology requires them to be always online. They are required to make sure that they are constantly connected to their digital system and able to react in the case of technical problems indicated by that system. This is the only way the farmers can ensure smooth operating of their farms. This 24/7 type of on-call duty was experienced as unpleasant and stressful by some of the interview partners. 
[T]his pressure to be always on duty, this level of on-call duty, that you have to have, that is indeed psychologically stressful. The physical strains are less [...] but the psychological stress is much more. [...] And because of this digitalisation step we have taken, it is like this, that you always check "Ok, do I have my mobile phone? Do I have enough battery? Is it possible that the system can reach me? Am I online?" And this, sure that is like, that you can never "switch off". That is definitely a critical issue. The other side of the coin. But actually, the advantages prevail, that is why I accept it. (Interview 6)

Besides the disadvantages described and experienced by the farmers, not one of the interview partners considered going back to a non-digitalised farm. Digitalised farming was perceived as easier, more diverse, and more flexible work, and even more interesting, especially for those farmers who showed some kind of technical affinity.

\subsection{Knowledge Requirements}

Farmers working in digitalised environments still need a strong background of agricultural basics like nutritional requirements of cattle, symptoms of diseases, or typical care procedures. At the same time, the interviewees emphasised that knowledge and skills connected to the use of computers and other kinds of mobile digital devices have been gaining importance. In general, it has been argued that farmers working on digital farms require some kind of basic understanding of how technology works to take care of the tasks and problems at hand.

Yes, one should be computer literate and probably also be able to use touch technology. [...] Yes, it is not an easy job any more as it used to be, now anything is done by machines, so you need some understanding of these machines and how to work the machines. (Interview 8)

Moreover, the relevance of knowledge and skills connected to the extraction, interpretation, and usage of data provided by the different sensors on their farms was described as highly important. Farmers are required to be able to distinguish relevant from less relevant data and to interpret data in reference to established norms of certain parameters and/or changes occurring over time. To do so, the data and information provided by the digital system need to be integrated with more traditional knowledge about farming processes or animals. 
If the cow deviates from its normal parameters, that I want to know. I am not interested whether it has slept 6 or 8 hours. I just want to know if she behaves somehow abnormally. Is there something different than usual? And then I can see this and draw my conclusions. What's happening? Why is she behaving like this? Sure, that, of course, requires experience. [...] And for instance, if I have taken care of their claws then the cows are a little bit confused, then the system is not helping. The parameters provided by the system will change due to this disturbance. That is why I must not over interpret the parameters on such days. (Interview 5)

\subsection{Learning Modes}

Most interviewees described that the knowledge and skills required to use the digital systems on their farms had not been covered or were only marginally covered in their initial (vocational) education. Instead, the predominant modes to acquire this body of knowledge were on-site training provided by the manufacturer of the digital farming technology as well as experiential and other informal learning activities. First, all interview partners reported that the manufacturers of the larger machines like milking robots provided a short but intense training period after the technology was bought and installed. That training was usually one to two days long; a trained service technician would spend the full 24 or 48 hours on the farm, instructing the farming staff on how to operate the technology and jointly working with the farmers to enable them to use the machines and computers in the context of their own farms. Only in a few instances was it reported that manufacturers or other training providers offered longer and more formalised learning opportunities. After the initial on-site training, learning was mostly experience-based. However, other learning opportunities emerged from reading professional literature like manuals or internet resources, and from discussions with befriended farmers that were usually related to some kind of trouble shooting.

I would say it like this, one gets the first instructions from the ones, that sells it to you or in the case of our milking robot, for instance, there was this additional person, when we switched, he was being here, he explained everything. The cattle had to be used to it and then he was here 24 hours, the full time, and he explained everything. (Interview 1)

Insights about the technological innovations existing in the farming domain and how such technology can be used were acquired through reading farming journals for practitioners, visiting trade fairs, or speaking with other farmers who had already digitalised their businesses. 


\section{Discussion}

This section sets out to discuss the findings. For this purpose, the first two subsections answer the research questions that guided this study: (a) How do farmers experience the changes from more traditional work to digitalised agriculture? and (b) What knowledge do farmers require on digitalised farms and how do they acquire it? It is followed by a short discussion of relevant limitations underlying the empirical work conducted.

\subsection{Experience of Digitalisation}

Digitalisation has changed farming from an occupation that was characterised by manual work involving mechanical tools into one that requires symbol manipulation using highly automatised digital technology. In particular, it is the more menial and physical demanding tasks that are taken over by machines (see, for similar findings, Butler et al., 2012; Vik et al., 2019). Instead, farmers have to work more often now with computers that allow them to monitor and control these systems. This work can be described as mostly cognitive rather than manual. In this way, the changes triggered by digitalisation can be interpreted as predicted in the specialisation scenario described above (see also Dworschak \& Zaiser, 2014). On the other hand, this is only true for trained staff or the owners of the farms. Farming aides, especially those without education who are appointed to manual routine tasks, may subsequently lose their jobs to machines. This can then be interpreted as evidence for the automation scenario. Taken together, these findings speak in favour of ideas put forward by Frey and Osborne (2017): Digitalisation leads to a loss of jobs formerly held by mostly low-educated staff and requires the remaining more capable workers to engage in more cognitively demanding work.

Another change in the daily work of farmers concerns the frequency with which they are in direct contact with their cattle, as also described by Butler et al. (2012) and Holloway et al. (2014). Due to shifts of tasks that require working with computers, farmers spend less time in the cowshed together with their livestock. In other words, digitalised work becomes more abstract and less concrete. Some authors would interpret this as a first sign of potential tendencies of alienation, where farmers might lose the connection to their cattle and the foundations of their work that then leads to a potential loss of meaning and identity (Holloway et al., 2014). At the same time, however, most farmers reported that they had the feeling that the new technology gives them an even deeper insight into their farms which helps them further to understand their livestock. The additional data bring them closer to their animals than they have ever been before. This speaks against potential tendencies of alienation.

In line with the findings reported by Butler et al. (2012) and Vik et al. (2019), all interview participants emphasised that the new technology has afforded them a greater degree of freedom to decide when to work and from where to work (see also Steeneveld et al., 
2012). This flexibility is gained mostly from the automation of processes as well as from new opportunities to monitor and control incidents at the farm remotely. In general, this new way of working is perceived as something desirable since it allows more self-determination and work-life balance. Nevertheless, this flexibility comes with a greater need of being constantly online so that the CPS may contact the farmer in the face of unexpected events or failure. Some farmers experience this requirement to be constantly on call as stressful (see also Butler et al., 2012). Within the digitalisation literature this phenomenon has been described as blurring boundaries of the private and professional spheres (Harteis, 2018). At the same time, one has to acknowledge that farming always has been an occupation where the private and professional spheres have been strongly intertwined.

\subsection{Knowledge Requirements and Learning}

Farmers need to be literate to use computer technology and to engage in a range of datarelated tasks. However, computer and data literacy as such are not sufficient. To realise the potential of the digital technology effectively and efficiently, farmers need to integrate knowledge of how digital systems of interconnected machinery and sensors work, including how to analyse the provided data with professional farming knowledge. They need to construct mental models that allow them to decide what data are relevant and how they are generated by what sensors, how reliable the generated information usually is, and how it connects with real-world phenomena of their livestock. Without such elaborated and fitting mental models, farmers might not use the full capacity of their digital system or-in the worst case-might make uninformed if not poor decisions, negatively affecting their cattle and business (after all, the data provided by digital systems ought to support decision-making: Ayre et al., 2019).

Apart from that, and in line with the general literature on digitalisation of work (Harteis, 2018), farmers need a good understanding of all production processes on their farm. Such knowledge is required to understand what data are automatically collected by the digital system through sensor technology and what data must be gathered in some other way. For instance, although certain illnesses can be detected using milk parameters, others do not manifest this way. It follows that farmers have to understand what data are collected, what conclusions can be drawn from the available data, and what additional data are required to assess the health of livestock. At the same time, farmers need to know about symptoms of health-related issues that can not be detected using the sensors in use but might only manifest themselves in sensual experiences (sounds, looks, smell etc.). A similar phenomenon has been reported in studies with mechanics and truck drivers that heavily rely on listening to the sound of machinery or engines to diagnose problems (Bauer et al., 2006; Lewis, 2011). Such often implicit knowledge is usually acquired through long-lasting contact with cattle that allows building up experiential knowledge structures that represent how healthy 
and less healthy cows look and behave (Boshuizen et al., 2020). The question of whether such knowledge can be sufficiently constructed in settings in which farmers have less and less direct contact with their livestock remains open. In the worst case, the predicted irony of automation (Bainbridge, 1983) might become reality in which farmers are not able to respond appropriately to particular issues on their farm, since digitalisation would have deprived them of drawing on relevant experiences that are compiled in implicit knowledge structures (see also Billett, 2018).

In addition, farmers need to know about issues that affect the processes on their farms. A typical example is when a cow gets antibiotics and its milk must therefore not be processed any further. In such cases the farmer needs to inform the CPS about this fact, otherwise the milk of the affected cow is put into the general tank and might spoil the whole daily yield. Without knowledge of how the production process is structured, this could lead to relevant financial losses for the farmer and health-related risks for their customers.

So how do farmers learn the knowledge and skills required to work in digitalised farming environments? First of all, all the farmers in this study had completed at least some vocational farming degree and had some years of experience in traditional livestock farming. So, they could all build upon a strong foundation of farming knowledge. At the same time, it was reported that their education did not cover the use of digital systems, or only in a very limited way. The knowledge and skills required to work with the machines were then mostly acquired through short instructions provided by the manufacturer of the technology, through daily experience, through reading codified information, and through discussions with other farmers. The relevance of peer-to-peer communication in the context of digital farming has already been emphasised by Kernecker et al. (2020). However, the former learning mode especially has to be assessed quite critically from an educational perspective. Whether the manufacturer really has an incentive to empower farmers to use the system they were sold in an independent way remains open for speculation. After all, it is normal practice to sell farmers maintenance services. In the worst case, it could be argued, farmers are intentionally tied to a single manufacturer with the aim to purchase services continuously from the very same company. From an educational perspective, this is largely undesirable since farmers might lose their professional sovereignty.

\subsection{Limitations}

The following limitations should be taken into account when interpreting the findings of this study: (a) Only 10 interview partners agreed to take part in this study, although a larger number of farmers had been invited. It remains unclear whether the farmers who did not agree to being interviewed would have answered differently due to different experiences with or different attitudes towards digitalisation. From our perspective, a relatively high risk exists 
that farmers who participated in this study were satisfied with the changes on their farms and felt rather competent with the digital technology in use. (b) Furthermore, the sample has to be described as rather small and all farmers were located in a part of Germany that has generally been quite open and welcoming to technological change in the recent past. It therefore remains open how generalisable the findings are either to the German context or the international one. (c) The interview participants all work on farms that are average size for the German context. It is therefore open how the findings might hold for small or very large farms.

\section{Conclusion}

The introduction of digital technology was perceived as something positive by the affected farmers: Work has become less menial and more flexible, and it allows for a better worklife balance due to a shift from manual tasks towards work that comprises mainly symbol manipulation and data interpretation. At the same time, however, the new technology requires farmers to be permanently on duty, which was sometimes described as stressful. It follows that farmers should be aware of both the positive effects of the introduction of digital technology on their farms and also the potential risks connected to the change.

The successful management and operation of digitalised farms requires farmers to construct elaborated mental models that contain traditional farming knowledge, a strong understanding of the production processes at their farm, and technological literacy. It is only such integrated knowledge that allows them to make full use of the new technology. It remains open how younger farmers, especially those who have not experienced traditional farming, build up such mental models. It is therefore required that both vocational and academic schools appropriately cover traditional as well as digital farming and that they help students to make the necessary connections between these knowledge domains. A stronger coverage of digital technology within farming degrees should also help farmers to remain more independent of manufacturers. A strong understanding of digital technology will help farmers to assess critically the services offered by manufacturers and consequently to maintain their professional sovereignty.

\section{Acknowledgements}

We are grateful for the help of Monika Dieckmann, Petra Fortmeyer and Leonie Gotzeina who helped in conducting the interviews as part of their Master's degree. 


\section{References}

Al-Ani, A. (2017). CPS and the worker: Reorientation and requalification? In S. Jeschke, C. Brecher, H. Song \& D. B. Rawat (Eds.), Industrial internet of things: Cybermanufacturing systems (pp. 563-574). Springer.

Ayre, M., Mc Collum, V., Waters, W., Samson, P., Curro, A., Nettle, R., Paschen, J.-A., King, B., \& Reichelt, N. (2019). Supporting and practising digital innovation with advisers in smart farming. NJAS - Wageningen Journal of Life Sciences, 90-91. https://doi.org/10.1016/j.njas.2019.05.001

Bauer, H. G., Böhle, F., Munz, C., Pfeiffer, S., \& Woicke, P. (2006). Hightech-Gespür: Erfahrungsgeleitetes Arbeiten und Lernen in hoch technisierten Arbeitsbereichen. Ergebnisse eines Modellversuchs beruflicher Bildung in der chemischen Industrie [Hightech sense: Experience-led work and learning in high technology work domains. Results of a pilot project in VET in the chemical industry]. Bertelsmann.

Bainbridge, L. (1983). Ironies of automation. Automatica, 19(6), 775-779. https://doi.org/10.1016/00051098(83)90046-8

Billett, S. (2018). Accessing and securing conceptual and symbolic knowledge required for digital era work. In C. Harteis (Ed.), The Impact of Digitalization in the Workplace (pp. 197-212). Springer. https://doi.org/10.1007/978-3-319-63257-5_13

Boshuizen, H. P. A., Gruber, H., \& Strasser, J. (2020). Knowledge restructuring through case processing: The key to generalise expertise development theory across domains? Educational Research Review, 29. https://doi.org/10.1016/j.edurev.2020.100310

Butler, D., Holloway, L., \& Bear, C. (2012). The impact of technological change in dairy farming: Robotic milking systems and the changing role of the stockperson. Journal of the Royal Agricultural Society of England, 173, 1-6.

Dworschak, B., \& Zaiser, H. (2014). Competences for cyber-physical systems in manufacturing - First findings and scenarios. Procedia CIRP, 25, 345-350. https://doi.org/10.1016/j.procir.2014.10.048

Eastwood, C., Klerkx, L., \& Nettle, R. (2017). Dynamics and distribution of public and private research and extension roles for technological innovation and diffusion: Case studies of the implementation and adaptation of precision farming technologies. Journal of Rural Studies, 49, 1-12. https://doi. org/10.1016/j.jrurstud.2016.11.008

Eteläpelto, A., Vähäsantanen, K., Hökkä, P., \& Paloniemi, S. (2013). What is agency? Conceptualizing professional agency at work. Educational Research Review, 10, 45-65. https://doi.org/10.1016/j. edurev.2013.05.001

Fischer, C., Goller, M., Brinkmann, L., \& Harteis, C. (2018). Digitalisation of work: Between affordances and constraints for learning at work. In D. Ifenthaler (Ed.), Digital Workplace Learning (pp. 227-249). Springer International Publishing. https://doi.org/10.1007/978-3-319-46215-8_13

Federal Ministry of Food and Agriculture. (2016). Betriebe mit Milchkuhhaltung nach Bestandsgrößenklassen [Farms with dairy cattle-Herd size classes]. FMFA. https://www.bmel-statistik.de/landwirtschaft/tierhaltung/rinderhaltung/

Frey, C. B., \& Osborne, M. A. (2017). The future of employment: How susceptible are jobs to computerisation? Technological Forecasting and Social Change, 114, 254-280. https://doi. org/10.1016/j.techfore.2016.08.019

Goller, M. (2017). Human agency at work: An active approach towards expertise development. Springer VS. 
Götz, K.-U., \& Duda, J. (2018). Methoden und Potenziale der Datenverarbeitung - Umsetzungsstrategien Tierhaltung, Tierernährung und Tierzüchtung [Methods and potential of data processing Application strategies livestock farming, livestock feeding, and livestock breeding]. In H. Wilhem Schaumann Stiftung (Eds.), 27. Hülsenberger Gespräche 2018. Landwirtschaft und Digitalisierung (pp. 132-137). H. Wilhelm Schaumann Stiftung.

Harteis, C. (2018). Machines, change and work: An educational view on the digitalization of work. In C. Harteis (Ed.), The impact of digitalization in the workplace (pp. 1-10). Springer. https://doi. org/10.1007/978-3-319-63257-5_1

Harteis, C., Goller, M., \& Fischer, C. (2019). Die Auswirkungen der Digitalisierung auf die Bedeutung beruflicher Qualifikation aus betrieblicher Sicht. In J. Seifried, K. Beck, B.-J. Ertelt, \& A. Frey (Eds.), Beruf, Beruflichkeit, Employability (pp. 239-253). wbv.

Herlitzius, T. (2018). Landtechnikentwicklung im Digitalisierungshype - "Evolutionär oder Disruptiv?" [Development of agricultural technology as digitalisation hype - "Evolutionary or disruptive?"]. H. Wilhem Schaumann Stiftung (Eds.), 27. Hülsenberger Gespräche 2018. Landwirtschaft und Digitalisierung (pp. 30-38). H. Wilhelm Schaumann Stiftung.

Holloway, L., Bear, C., \& Wilkinson, K. (2014). Robotic milking technologies and renegotiating situated ethical relationships on UK dairy farms. Agriculture and Human Values, 31(2), 185-199. https://doi.org/10.1007/s10460-013-9473-3

Kagermann, H. (2015). Change through digitization-Value creation in the age of industry 4.0. In H. Albach, H. Meffert, A. Pinkwart, \& R. Reichwald (Eds.), Management of permanent change (pp. 23-45). Springer. https://doi.org/10.1007/978-3-658-05014-6_2

Kernecker, M., Knierim, A., Wurbs, A., Kraus, T., \& Borges, F. (2020). Experience versus expectation: Farmers' perceptions of smart farming technologies for cropping systems across Europe. Precision Agriculture, 21(1), 34-50. https://doi.org/10.1007/s11119-019-09651-z

Kuckartz, U. (2014). Qualitative text analysis: A guide to methods, practice \& using software. SAGE.

Letmathe, P., \& Schinner, M. (2017). Competence management in the age of cyber physical systems. In S. Jeschke, C. Brecher, H. Song, \& D. B. Rawat (Eds.), Industrial internet of things: Cybermanufacturing systems (pp. 595-614). Springer.

Lewis, J. C. (2011). Dynamic integrated learning: Managing knowledge development in road transport [Doctoral dissertation, Griffith University].

Organisation for Economic Co-operation and Development. (2019). Digital opportunities for better agricultural policies. OECD Publishing.

Pfeiffer, S. (2018). The "Future of Employment" on the shop floor: Why production jobs are less susceptible to computerization than assumed. International Journal for Research in Vocational Education and Training, 5(3), 208-225. https://doi.org/10.13152/IJRVET.5.3.4

Schreier, M. (2012). Qualitative content analysis in practice. SAGE.

Sponchioni, G., Vezzoni, M., Bacchetti, A., Pavesi, M., \& Renga, F. M. (2019). The 4.0 revolution in agriculture: A multi-perspective definition. Proceedings of the XXIV Edition, 143-149.

Steeneveld, W., Tauer, L. W., Hogeveen, H., \& Oude Lansink, A. G. J. M. (2012). Comparing technical efficiency of farms with an automatic milking system and a conventional milking system. Journal of Dairy Science, 95(12), 7391-7398. https://doi.org/10.3168/jds.2012-5482

Vik, J., Stræte, E. P., Hansen, B. G., \& Nærland, T. (2019). The political robot - The structural consequences of automated milking systems (AMS) in Norway. NJAS - Wageningen Journal of Life Sciences, 90-91. https://doi.org/10.1016/j.njas.2019.100305 
Wolfert, S., Ge, L., Verdouw, C., \& Bogaardt, M.-J. (2017). Big data in smart farming - A review. Agricultural Systems, 153, 69-80. https://doi.org/10.1016/j.agsy.2017.01.023

World Economic Forum. (2016). The future of jobs. Employment, skills and workforce strategy for the fourth industrial revolution. http://www3.weforum.org/docs/WEF_Future_of_Jobs.pdf

\section{Biographical Notes}

Dr Michael Goller is currently a visiting professor of Empirical Methods in Educational Research at the University of Jena and a research associate and post-doc at the Institute of Educational Science at Paderborn University. Between October 2018 and March 2020, he served as visiting professor at the University of Bamberg. His current research interests comprise, among others, expertise development and workplace learning in general including in the particular context of digitalisation, as well as learning and development of students at the boundary of institutionalised and less institutionalised learning environments like internships or particular learning arrangements in VET.

Dr Carina Caruso is a post-doc at the Institute of Educational Science at the Paderborn University in German focussing on empirical educational research. Her research interests comprise students' professional learning in internships, teachers' professional development, and expertise development within the context of digitalised work environments.

Dr Christian Harteis is full professor of Educational science, educational management and research on further education at Paderborn University (Germany). His research interests are related to issues of workplace and professional learning, intuition, learning from errors and learning in the face of work-related digitalisation processes. He acts, together with Stephen Billett, as editor-in-chief for the journal Vocations and Learning: Studies in Vocational and Professional Education. 